\title{
A quebra do peso mexicano: causas, consequências e recuperação*
}

The Mexican Peso break: causes, consequences and recovery

TIMOTHY KESSLER $*$

RESUMO: Este artigo traça as maneiras pelas quais fatores políticos, econômicos, domésticos e internacionais convergiram para provocar uma enorme crise financeira no México em 1994/5, bem como as consequências dessa crise para futuros esforços de reforma. O autor argumenta que a manutenção de uma taxa de câmbio supervalorizada antes da crise permitiu ao partido PRI apelar para uma ampla gama de interesses domésticos. Os investidores internacionais, que detinham sem precedentes US\$ 34 bilhões em ações mexicanas em 1994, foram igualmente inflexíveis na defesa da taxa de câmbio ancorada. No entanto, ao tentar apaziguar interesses nacionais e estrangeiros, o governo Salinas perdeu o controle dos fundamentos macroeconômicos. Enquanto a combinação de um empréstimo multilateral maciço e a mudança para uma taxa de câmbio flutuante abriram o caminho para a rápida recuperação econômica do México, o principal legado da crise foi o fim político do PRI. Embora a liberalização política certamente não fizesse parte do plano original do PRI, graças a seus próprios imprudentes erros políticos, o principal legado da crise do peso foi o advento de políticas mais abertas no México. Por esse motivo, a política de formulação de políticas econômicas sob o novo governo Fox pode não estar tão bem organizada quanto estava com o PRI, mas já existem sinais sem precedentes de debate, prestação de contas e compromisso.

PALAVRAS-CHAVE: Crise cambial; crise do peso mexicano; globalização.

ABSTRACT: This article traces the ways in which political, economic, domestic, and international factors converged to provoke a massive financial crisis in Mexico in 1994/5, as well as the consequences of this crisis for future reform efforts. The author argues that the maintenance of an overvalued exchange rate prior to the crisis enabled the ruling PRI party to appeal to a broad range of domestic interests. International investors, who held an unprecedented $\$ 34$ billion in Mexican equities in 1994, were equally adamant in defending the anchored exchange rate. However, in attempting to appease both domestic and foreign interests, the Salinas administration lost control of the macroeconomic fundamentals. While

\footnotetext{
* Tradução de Maria Cristina Godoy.

**Associate director of the Partnership for Policy Dialogue based at Stanford University and the Carnegie Endowment for International Peace, Stanford/CA, U.S.A.
} 
the combination of a massive multi-lateral loan and the shift to a floating exchange rate paved the way for Mexico's rapid economic recovery, a main legacy of the crisis was the political demise of the PRI. Although political liberalization was certainly not part of the PRI's original game plan, thanks to its own reckless policy errors, a main legacy of the peso crisis was the advent of more open politics in Mexico. Because of this, the politics of economic policymaking under the new Fox administration may not be as neatly packaged as under the PRI, but there are already unprecedented signs of debate, accountability, and compromise. KEYWORDS: Currency crisis; Mexican peso crisis; globalization.

JEL Classification: F31; F32; F62.

A desvalorização do peso mexicano em dezembro de 1994 foi o primeiro de uma série de colapsos financeiros não previstos que desmontou a sabedoria convencional sobre o relacionamento entre a disciplina de mercado e a estabilidade econômica. O México era, afinal de contas, um modelo do Consenso de Washington. ${ }^{1}$ No início dos anos 90 o governo havia aberto o comércio, transformando um enorme déficit fiscal em superávit, domado a inflação e privatizado quase todas as empresas públicas, inclusive o sistema bancário e a Telmex, o monopólio telefônico. Embora o sucesso do México em alcançar a disciplina econômica tenha continuado a contrastar com seu crescimento bastante lento, os proponentes da reforma alegaram que os fundamentos do desenvolvimento sustentável haviam sido estabelecidos. O colapso da moeda em 1994 e a terrível recessão de 1995 levaram a uma explosão de pesquisas sobre o que havia dado errado no México. No entanto, na sequência de devastadoras desvalorizações em vários dos maiores mercados emergentes do mundo, inclusive Rússia, Coréia do Sul, Indonésia e Brasil, a experiência mexicana é vista agora como precursora de um novo fenômeno econômico: a volatilidade dos mercados globais de capital. Mas o comportamento dos investidores globais, embora claramente um fator importante da história da instabilidade financeira nos mercados emergentes, não foi a única causa. É claro que nem todos os mercados emergentes sofreram desvalorizações abruptas, mas os que as experimentaram quebraram em momentos diferentes, em graus variados e por razões diferentes. O caso mexicano demonstra que o impacto do capital internacional é fundamentalmente condicionado por políticas e diretrizes internas.

Os aspectos econômicos da quebra do peso são agora bem compreendidos. A relação entre o déficit em conta corrente e a taxa de câmbio representou um círculo vicioso no modelo macroeconômico do México. No início da administração de Carlos Salinas de Gortari (1988-94), o Ministério da Fazenda adotou uma crawling peg, uma faixa restrita dentro da qual o peso ficava atrelado ao dólar e podia sofrer

\footnotetext{
${ }^{1} \mathrm{O}$ "Consenso de Washington" representa um acordo geral entre o governo dos EUA, agências de empréstimo internacionais e economistas conceituados, de que o mercado livre e a redução do papel do Estado são os fundamentos do crescimento sustentado nos países em desenvolvimento. Ver John Williamson, ed., Latin American Adjustment: How Much Has Happened? (Institute for International Economics, 1990).
} 
ligeiras flutuações diárias. Como a inflação mexicana aumentou bem acima da dos EUA, o impacto da crawling peg foi uma valorização gradual, porém cumulativa da moeda. Em 1992, muitos economistas manifestaram preocupação com a capacidade de sustentação da peg. Como a crawling peg não conseguiu impedir a supervalorização do peso, as importações acabaram ficando baratas e o déficit em conta corrente aumentou rapidamente.

Para cobrir o desequilíbrio, o Banco Central foi forçado a comprar grandes quantidades de dólares do exterior, o que, por sua vez, exigiu que o Estado abrisse o mercado de títulos aos investidores externos. A fim de sustentar a confiança do setor externo, o peso foi mantido artificialmente forte. No entanto, como a moeda supervalorizada atraiu mais importações, o desequilíbrio comercial aumentou e teve de ser coberto com entradas cada vez maiores de capital externo. Mesmo se o México tivesse reduzido pela metade o crescimento das importações entre $1994 \mathrm{e}$ 2000 e tivesse aumentado pela metade suas exportações, o déficit comercial ainda assim teria aumentado cerca de $50 \%$, exigindo mais de US\$ 100 bilhões de capital novo para cobrir o rombo. ${ }^{2}$ Qualquer interrupção na entrada de capitais teria tornado insustentável a crawling peg.

Mudanças econômicas internacionais combinaram-se com as vulnerabilidades financeiras e com a instabilidade política do México, para provocar uma rápida e maciça fuga de capitais. Em 1994 o crescimento moderado dos EUA alimentou os temores de inflação e levou o Banco Central dos EUA a quase dobrar suas taxas de juros, de $3 \%$ para $5,5 \%$. Como consequência, a taxa de retorno de quase todos os títulos norte-americanos aumentou, tornando estes investimentos altamente seguros muito mais atraentes do ponto de vista financeiro do que os emitidos por qualquer país em desenvolvimento, inclusive o México. Durante esse mesmo ano, aumentou a percepção dos investidores sobre a instabilidade mexicana, depois de assassinatos políticos e do levante de Chiapas. Na segunda metade do ano, as entradas de capital externo caíram $75 \%$. Com os investimentos em mercados maduros gerando então maiores lucros, os administradores do dinheiro global encenaram uma "fuga para a qualidade", o que colocou o peso sob intensa pressão. Num esforço desesperado para defender a taxa de câmbio, a administração Salinas esvaziou as reservas em moeda estrangeira, de US\$ 30 bilhões para apenas US\$ 6 bilhões no final de 1994. Só em dezembro desse ano, entre US\$ 4 bilhões e US\$ 6 bilhões deixaram o país.

Em 20 de dezembro de 1994, apenas três semanas após o início do governo de Ernesto Zedillo Ponce de Léon (1994-2000), o Ministério da Fazenda ampliou a banda cambial em 15,3\%. Os investidores entraram em pânico e iniciaram uma corrida ao peso. No dia seguinte, a peg (paridade) foi abandonada e o peso flutuou livremente com relação ao dólar. $\mathrm{O}$ valor do peso imediatamente caiu à metade de seu valor nominal, mergulhando o México numa depressão surpreendentemente profunda.

\footnotetext{
${ }^{2}$ El Inversionista Mexicano, 29 de agosto de 1994, p.2. Todos os valores em dólar são dólares dos EUA.
} 
Este capítulo oferece hipóteses acerca da manutenção de um regime cambial cada vez mais insustentável. A seguir, explora as consequências do colapso do peso, avalia o desempenho econômico do México a partir da crise e examina o legado político da desvalorização.

\section{EXPLICAÇÕES ALTERNATIVAS DO REGIME CAMBIAL}

A origem da peg foi a inflação persistentemente alta. Apesar de inúmeras reformas econômicas levadas a cabo durante a administração de Miguel de la Madrid Hurtado (1982-88) - desde rígidos cortes nos gastos públicos à liberalização do comércio - as autoridades financeiras não conseguiam controlar os preços. A inflação subiu até bem acima de $100 \%$ ao ano no meio da década de 80 . O terremoto da Cidade do México em 1985 e a queda no preço do petróleo em 1986 arruinaram por completo esses dolorosos esforços de estabilização, levando o governo a orquestrar o primeiro de uma longa série de "pactos sociais" entre capital e trabalho para conter preços e salários. Em julho de 1987, Carlos Salinas, então Ministro do Orçamento e do Planejamento, anunciou a luta contra a inflação como a principal prioridade da estratégia econômica, revelando um plano de estabilização que substituiu a flutuação da moeda por uma fixed peg, a fim de colocar um freio nas expectativas de aumentos de preços.

Quando Salinas se tornou presidente, os efeitos estabilizadores da peg já se haviam tornado evidentes. A inflação estava, finalmente, sendo domada. Durante o primeiro mês de Salinas como presidente, o governo relaxou um pouco a taxa fixa, estabelecendo a crawling peg. Nos seis anos seguintes, a administração se recusou a alterar a política cambial, apesar das crescentes evidências de supervalorização e dos déficits comerciais cada vez maio res.

A posição contrafactual implícita assumida pelos críticos de Salinas era de que, se tivesse permitido uma leve desvalorização antes dos fatídicos eventos de 1994, seja expandindo a banda, seja fazendo flutuar o peso, ele teria salvado o México do colapso financeiro. Nos primeiros anos da década, a supervalorização do peso era moderada, as relações com os investidores internacionais eram excelentes e, com altos níveis de reservas, o governo podia defender-se com credibilidade contra a especulação. Olhando retrospectivamente, parece provável que permitir que os mercados de câmbio determinassem o valor da moeda durante o início dos anos 90 - ou mesmo no início de 1994 - teria resultado num ajuste e não numa crise.

\section{MÁ SORTE E ERROS}

Alguns desculpam a falha da equipe de Salinas em agir no tempo certo argumentando que a política cambial estava totalmente correta, mas simplesmente saiu dos trilhos em virtude de eventos imprevisíveis. Se a violência política e a alta dos juros do Banco da Reserva Federal dos EUA não tivessem ocorrido em 1994, não 
teria sido implausível um cenário de continuação da estabilidade e de manutenção das entradas de capital. Na verdade, talvez Salinas tivesse conseguido a estabilidade econômica e a confiança do investidor necessárias para uma desvalorização gradual e um pouso suave durante os seis anos do governo Zedillo. Outra explicação - de todo compatível com a anterior - é a incompetência da equipe econômica de Zedillo. Jaime Serra, ministro do Comércio durante a administração Salinas e depois ministro da Fazenda do Presidente Ernesto Zedillo, foi severamente criticado (e destituído) por enervar os investidores com pronunciamentos desastrosos sobre objetivos das políticas e com informações inconsistentes.

Ambas as explicações têm certo mérito. Os eventos de 1994 foram claramente imprevisíveis, e a inépcia da administração Zedillo ao ampliar a crawling peg confundiu e enraiveceu os investidores. No entanto, é precisamente a alta vulnerabilidade do México ao comportamento do investidor externo que necessita de explicação. As entradas de capital externo dependiam da continuação de um cenário extremamente favorável - taxas de juros historicamente baixas nos EUA e oportunidades menos atraentes para os investidores em outros mercados emergentes. A administração Salinas tornou a estabilidade econômica refém de acontecimentos muito além de seu controle e assim expôs o México às incertezas dos fluxos do capital internacional. Embora a equipe econômica de Salinas tenha jurado salvaguardar a economia mexicana acima de tudo, ela no final apostou a estabilidade financeira na continuação indefinida de um status quo sobre o qual o país não tinha virtualmente nenhum controle.

$\mathrm{O}$ argumento de que Zedillo havia destruído seis anos de trabalho duro de Salinas em menos de três semanas - Salinas caracterizou a quebra como "os erros de dezembro" - toma erroneamente a causa pelo efeito. Não obstante o anúncio malfeito de que a banda cambial seria autorizada a flutuar, não está claro como a nova administração teria podido defender o peso por mais tempo. Com as reservas de moeda forte diminuídas e com o capital externo correndo para fora do país, a simples aritmética já sugeria que a crawling peg não poderia continuar indefinidamente. Além disso, à medida que o peso se foi tornando mais supervalorizado a cada momento, a credibilidade da defesa do governo se foi tornando mais fraca. Quanto maior a espera, mais sérias seriam as reações esperadas ao ajuste do peso, e mais vulnerável se tornaria o governo a acusações de fraqueza ou de falta de decisão. Se houve um momento ideal para a mudança do regime cambial, este se deu durante o governo de Salinas.

\section{PRESSÕES INTERNACIONAIS}

A explicação mais sólida para a resistência de Salinas em corrigir a taxa de câmbio é a pressão externa para manter o status quo. A fonte mais visível de influência externa provinha da absoluta prioridade que o governo mexicano havia colocado em garantir a entrada do México na NAFTA, Associação Norte-Americana de Livre Comércio (North American Free Trade Agreement). Como o déficit 
comercial do México com os Estados Unidos enfraquecia, os argumentos de que a integração econômica destruiria os empregos dos norte-americanos, o peso forte pode ter contribuído indiretamente para o apoio à associação no Congresso norte-americano. No entanto, é difícil atribuir grande importância política a algo tão abstrato e técnico como a largura da banda da crawling peg mexicana, particularmente no início dos anos 90, quando as negociações da NAFTA estavam em curso. Eram poucos os norte-americanos que sabiam qual era a taxa de câmbio peso-dólar ou porque ela era potencialmente importante - sobretudo se comparada às questões de trabalho e padrões ambientais, muito mais adequadas às manchetes dos jornais. Embora o alargamento da banda em 1992 ou no início de 1993 tivesse provavelmente diminuído o superávit comercial dos EUA com o México, ele também teria angariado para o governo mexicano elogios dos principais economistas internacionais. Em resumo, o debate nos Estados Unidos sobre a desvalorização do peso em 1992 ou 1993 teria sido provavelmente um acontecimento político sem importância. Além disso, a prioridade de aprovar a NAFTA não poderia ter influenciado a política cambial em 1994, pois a associação de livre comércio entrou em vigor no primeiro dia daquele ano.

Outra fonte de pressão internacional veio dos mercados de capital. Após as desvalorizações no Leste da Ásia, na Rússia e no Brasil, houve crescente reconhecimento do papel do capital internacional no desencadeamento de crises monetárias domésticas. A volatilidade do hot money - conjunto de capitais que pode ser rapidamente investido e sacado - foi identificada como uma importante restrição sobre a capacidade dos governos nos mercados emergentes de tomar qualquer atitude que possa minar a confiança dos investidores externos num horizonte de prazo curtíssimo.

Embora a influência do capital internacional sobre a política nacional seja tipicamente gerada através de sinais anônimos do mercado, no caso do México tal pressão foi bastante direta. O Weston Forum, um consórcio internacional de instituições financeiras, fez enormes investimentos nos títulos do governo mexicano no início dos anos 90. Ele incluía algumas das principais companhias de investimento do mundo, como Fidelity Investment Company, Soros Fund Management, Salomon Brothers, Nomura Securities, e o Grupo Weston. Em abril de 1994, depois de uma queda no valor do peso em relação ao dólar, o fórum encontrou-se secretamente com Guillermo Ortiz, então vice-ministro da Fazenda, e com administradores do Banco Central para dar conselhos sobre a direção da política econômica mexicana. De acordo com um relato do Wall Street Journal, "as sugestões foram agressivas". Os financistas pediram aos funcionários mexicanos que suspendessem as pequenas desvalorizações diárias permitidas pela crawling peg, que aceitassem que o governo mexicano assumiria as perdas incorridas pelas flutuações da taxa de câmbio além da banda atual, e que lhes permitisse aumentar o patamar de sua carteira de investimentos em dólar. Além disso, sugeriram que, assim que adotasse tais medidas, o México receberia até US\$ 17 bilhões de novos investimentos do consórcio e de seus 
associados. ${ }^{3}$ Como descreveu posteriormente o jornalista Douglas Payne, "Na verdade, o fórum queria que o México continuasse a supervalorizar o peso e que assumisse o risco... [A pressão do Weston Forum] explica suficientemente por que o governo mexicano adotou políticas que levaram ao colapso [do peso]". ${ }^{4}$

Outra evidência da pressão global foi a rápida reestruturação da dívida pública mexicana, de títulos do Tesouro em pesos, em geral chamados de cetes, para títulos em dólar, chamados de tesobonos. De acordo com o então ministro da Fazenda Pedro Aspe, a criação do tesobono representou "o compromisso voluntário do governo de cumprir a planejada disciplina nas finanças públicas" ${ }^{5}$ ou seja, uma garantia aos investidores de que não deixaria a moeda cair. Embora o novo instrumento de hedging tivesse recebido pouca atenção desde sua criação em 1989, em 1994 o volume de tesobonos em circulação atingiu subitamente quase US\$ 30 bilhões. ${ }^{6}$ Essa dramática alteração na estrutura da dívida pública mexicana indicou uma perda de confiança entre os investidores na moeda mexicana. Além disso, como os tesobonos eram indexados ao dólar, essa alteração assegurou que qualquer desvalorização aumentaria a dívida pública do governo em termos absolutos.

Citando táticas de coerção explícitas, bem como pressões mais sutis exercidas pelos mercados de capital, alguns alegaram que a comunidade internacional de investimentos manteve a taxa de câmbio mexicana como refém. Como a lucratividade dos instrumentos financeiros em pesos dependia diretamente da força da moeda, e como os instrumentos em dólar tinham de ser pagos em pesos, os tecnocratas mexicanos viram-se presos numa armadilha: eles só poderiam evitar a fuga de capitais mantendo uma política cambial que era, a longo prazo, insustentável. Era claro que o ambiente econômico externo tinha importância.

Mas a pressão exercida pelos investidores globais sobre o governo mexicano pressupõe uma taxa de câmbio já perigosamente supervalorizada. A decisão de manter a crawling peg, embora influenciada pelos investidores externos, era também um produto da determinação interna de manter uma taxa de câmbio semi-fixa, o que exigia entradas, cada vez maiores, de capital externo. Embora a comunidade internacional de investimentos tivesse claramente conseguido um poder de ação sobre a política monetária mexicana em 1994, esse poder era resultante, em grande escala, de decisões anteriores tomadas por uma administração cujo objetivo primário era retomar as vantagens políticas do partido dominante.

\footnotetext{
${ }^{3}$ Wall Street Journal, 14 de junho de 1994, p.A6.

${ }^{4}$ Douglas Payne, "Wall Street Blues”, New Republic, 13 de março de 1995, p. 22.

${ }^{5}$ Pedro Aspe, “Macroeconomic Stabilization and Structural Change in Mexico”, European Economic Review, vol. 36 (1992), p. 325.

${ }^{6}$ El Inversionista Mexicano, 25 de julho de 1994; El Financiero, 3 de novembro de 1994, p. 3A.
} 


\section{DESAFIOS POLÍTICOS À HEGEMONIA DO PARTIDO REVOLUCIONÁRIO INSTITUCIONAL}

A raiz da adesão do governo mexicano ao regime da taxa de câmbio foi a política interna. No final dos anos 80 o Partido Revolucionário Institucional (PRI), dominante, enfrentou seu primeiro desafio eleitoral genuíno. O descontentamento popular com a corrupção, com a instabilidade e com padrões de vida corroídos estava cobrando seu preço, e partidos de oposição viáveis ameaçavam conquistar eleitores tanto da direita quanto da esquerda. A eleição presidencial de 1988 foi a mais contestada da história mexicana; a margem de vitória de Salinas, segundo os padrões do PRI, foi bastante estreita. Na realidade, o PRI foi amplamente acusado de usar de fraude eleitoral para roubar a eleição da Frente Democrática Nacional (FDN), a coalizão de esquerda que mais tarde se tornou o Partido da Revolução Democrática (PRD). A liderança do PRI estava convencida de que teria de conquistar votos através de melhor desempenho económico, a fim de manter o controle do sistema político.

A desvalorização havia prejudicado a legitimidade e a credibilidade que o PRI detinha no passado. Cada um dos três presidentes anteriores havia permitido que o peso entrasse em colapso. O presidente Luis Echeverría (1970-76) terminou seu mandato de seis anos com uma grande desvalorização. O presidente José López Portillo (1976-82), que declarou que "o presidente que desvaloriza fica desvalorizado", lamentaria depois ter jurado publicamente defender o peso "como um cão" pouco antes de ser forçado a deixar que a moeda caísse, ao final de seu mandato. O presidente de la Madrid não teve habilidade para domar uma inflação de três dígitos durante a maior parte de seu mandato. Os mexicanos acabaram por identificar a moeda enfraquecida não apenas com inflação alta, recessão e incompetência governamental, mas também com humilhação nacional. Com a memória dos anos 80 ainda viva, mesmo uma pequena desvalorização, com a subsequente inflação, poderia com certeza expor a administração Salinas a críticas e a novas acusações de má gestão do PRI.

Associados à generalizada suspeita popular de desvalorização estavam diversos grupos políticos internos que explícita ou implicitamente apoiavam a manutenção da crawling peg. Grandes corporações, particularmente os grupos financeiro-industriais (conglomerados) dos quais dependia o novo modelo mexicano de crescimento orientado para o exterior, haviam assumido altos níveis de endividamento em moeda estrangeira desde o final dos anos 80 . Entre os 59 maiores grupos econômicos, o endividamento em dólar dobrou entre 1988 e 1991, atingindo mais da metade do passivo total. ${ }^{7}$ Não apenas as taxas de juros nos mercados globais eram menores do que as taxas internas, mas o peso forte sustentava essencialmente a capacidade das corporações de tomar empréstimos no exterior. Qualquer desvalo-

\footnotetext{
${ }^{7}$ Celso Garrido, "National Private Groups in Mexico: 1987-1993”, Cepal Review, vol. 53 (1994), pp. $159-75$.
} 
rização se traduziria diretamente num aumento do peso de sua dívida. E ainda, como os principais exportadores do México eram também os principais importadores, o grupo político natural a favor da desvalorização se achava diluído. ${ }^{8}$

Dentro da comunidade financeira, os proprietários dos bancos recém-privatizados representavam um grupo político em particular influente de apoio ao peso forte. Esses proprietários, muitos dos quais haviam feito fortunas no mercado de títulos durante os anos 80 emprestando dinheiro ao governo e especulando no mercado de ações, se haviam tornado a elite econômica do México. Eles forneciam ao PRI apoio político para a reforma e importantes contribuições financeiras, enquanto a administração Salinas lhes fornecia ampla proteção contra a competição. Esse pequeno, porém, poderoso grupo obteve lucros sem precedentes durante os anos 90, tomando empréstimos em dólar no exterior a taxas internacionais e emprestando pesos no país com enormes margens de juros. ${ }^{9}$ Qualquer ajuste no regime monetário teria minado esse arranjo lucrativo, e enfraquecido uma das mais importantes e bem estabelecidas alianças do PRI.

O movimento sindical juntou-se às grandes empresas no apoio à crawling peg, porque a inflação alta havia corroído seriamente os salários reais dos trabalhadores. A compressão dos salários foi exacerbada ainda mais pela série de pactos sociais que o PRI havia feito: acordos oficiais negociados periodicamente para garantira estabilidade macroeconômica, obrigando o governo a cumprir promessas relativas aos gastos, à tributação e aos déficits. Em retorno, os trabalhadores concordavam em reduzir suas demandas salariais e o capital consentia em conter as altas de preços. Embora os sindicatos fizessem objeções (sem muita força) à estratégia de liberalização da administração Salinas, eles concordavam inteiramente com a manipulação da moeda para combater a inflação e apoiavam fortemente a peg cambial. Ao final da administração Salinas, o item crawling peg continuava sendo " o elemento mais essencial do pacto". ${ }^{10}$

Finalmente, a classe média, embora desorganizada, beneficiava-se de um peso supervalorizado que subsidiava o consumo. Um dos maiores benefícios que o peso forte proporcionava a esse grupo era o maior poder de compra. ${ }^{11} \mathrm{Na}$ medida em

\footnotetext{
${ }^{8}$ Embora as "maquiladoras" de propriedade de estrangeiros, como as produtoras de carros e eletrônicos, tenham tradicionalmente importado a grande maioria de seus componentes de seu país de origem, as indústrias manufatureiras domésticas são também grandes importadoras. De 1989 a 1993, enquanto as exportações mexicanas "não maquila" cresceram $31,9 \%$, de US $\$ 22,8$ bilhões para US\$ 30 bilhões, num crescimento anual de $7,2 \%$, as importações "não maquila" tiveram um espantoso aumento de $109 \%$, de US\$ 23,4 bilhões para US\$ 48,9 bilhões, numa média de $20,2 \%$ ao ano (El Inversionista Mexicano, 29 de agosto de 1994).

${ }^{9}$ Timothy P. Kessler, Global Capital and National Politics: Reforming Mexico's Financial System (Westport, Conn.: Praeger, 1999, pp. 90-101)

${ }^{10}$ Uhran Demirors, “Credibility of Exchange-Rate Policy Wins Foreign Investors' Favor in Latin America”. Latin American Money Markets (supplement to LatinFinance) (janeiro-fevereiro de 1994), p. 6.

${ }^{11}$ Ver Manuel Pastor, "Pesos, Policies, and Predictions", in Carol Wise, ed., The Post-NAFTA Political Economy (Pennsylvania State University Press, 1998).
} 
que a peg tornava mais barata a dívida externa, esta também subsidiava bens e serviços como alimentos e artigos de luxo importados, bens de consumo duráveis, viagens ao exterior e produtos manufaturados domésticos feitos com insumos externos. Muitos desses bens se haviam tornado importantes símbolos culturais de prestígio e sofisticação. A moeda forte proporcionava, assim, bens de alto valor econômico a um grupo crucial, cujo apoio eleitoral o PRI tentava retomar, depois do perigoso namoro dos funcionários administrativos e profissionais com os partidos de oposição em 1988.

Compreensivelmente, os partidos de oposição do México não fizeram nada para desafiar a política cambial do PRI. Embora exigir a desvalorização pudesse ter angariado elogios de alguns economistas e investidores internacionais, teria significado suicídio político. Com a maioria dos mexicanos ainda se queixando, após mais de uma década de recessão, de que seu dinheiro podia comprar muito pouco, somente um político pouco hábil alegaria que o peso estava valendo demais.

Em suma, interesses diferentes e poderosos tornaram politicamente imprudente para a administração Salinas mexer com um regime cambial que havia claramente ultrapassado sua utilidade econômica. A imposição original da peg justificava-se em termos técnicos - colocar um freio à inflação-, mas, com o tempo, essa política gerou amplos grupos de interesse contra o ajuste, que acabaria por minar o objetivo original de recuperação da estabilidade macroeconômica. Para esses grupos, uma moeda sólida representava a pedra de toque do novo modelo. A inflação paulatinamente decrescente e o aumento do poder de compra eram evidências de que o modelo estava dando certo. Nos últimos anos do mandato de Salinas, os próprios critérios do PRI de sucesso econômico haviam sido amplamente aceitos pelos eleitores, que agora tinham escolhas eleitorais reais. Embora enfrentasse déficits comerciais crescentes e entradas de capital volátil, o governo mexicano tinha muito pouco espaço político para manobrar a política monetária. Embora o PRI tivesse habilidade para vender reformas econômicas difíceis como chave da estabilidade e do crescimento, a taxa de câmbio tornou-se o indicador pelo qual seria julgado o desempenho econômico do governo.

\section{CONSEQUENNCIAS DO COLAPSO}

A desvalorização de dezembro de 1994 teve um impacto devastador sobre o bem-estar econômico e a estabilidade financeira do México. Além disso, contribuiu para uma mudança fundamental no sistema político e para o fim da hegemonia do PRI. O que pegou muitos observadores de surpresa, depois de anunciada a flutuação, foi o quanto os mercados globais de capital rejeitaram o peso. Quase da noite para o dia, o valor da moeda mexicana caiu pela metade, e continuou a cair ainda mais durante o ano de 1995 (ver figura 3.1). Nem mesmo o cálculo mais alarmista de supervalorização feito antes da quebra teria sugerido que o peso estava duas vezes mais forte do que o mercado aceitaria. 


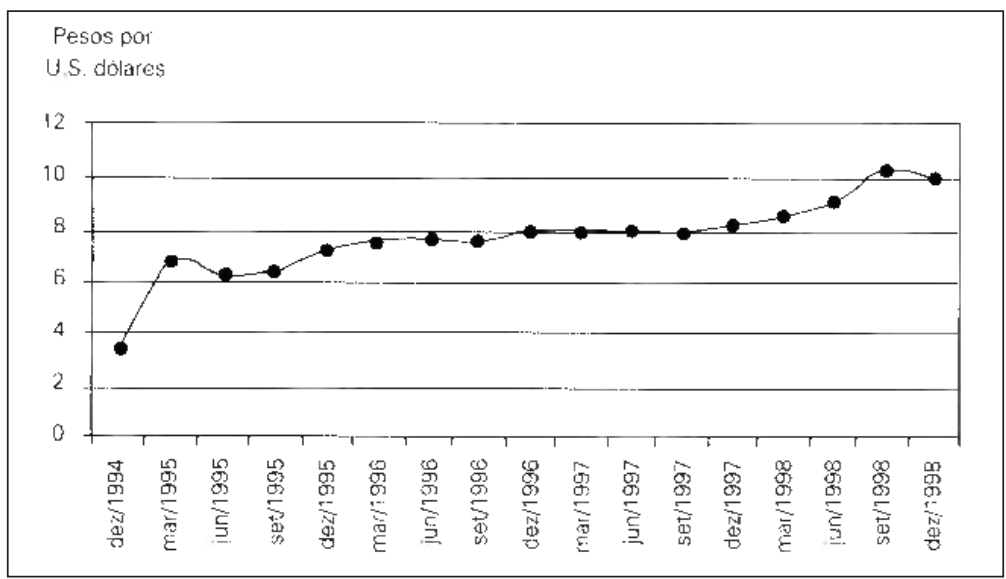

Fonte: Banco de México, Indicadores Econômicos

O México caiu numa recessão econômica mais profunda do que qualquer outra pela qual tivesse passado. O desemprego foi às alturas, inchando as fileiras da economia informal e colocando pressões ainda mais fortes sobre a baixa dos salários em todos os mercados de trabalho do país. $\mathrm{Na}$ economia formal, a inflação e a desvalorização corroeram os salários reais. Apenas três meses após a desvalorização, a economia mexicana estava irreconhecível, com o consumo tendo sido reduzido à metade. As vendas de automóveis caíram mais de $60 \%$ entre janeiro e fevereiro de 1995 , enquanto as vendas nos restaurantes caíram entre $20 \%$ e $40 \%$. Os hospitais e serviços médicos privados caíram $40 \%$, e artigos de luxo como as passagens aéreas internacionais despencaram cerca de $75 \%$.

Um dos efeitos mais devastadores da crise foi a ampliação da violência social. A Cidade do México, com um quarto da população do México, sofreu uma onda de crimes sem precedentes. Roubo e assalto à mão armada tornaram-se comuns. Táxis, que agora transportavam passageiros até assaltantes armados, tornaram-se emblemáticos do perigo. Os sequestros não mais visavam apenas os ricos executivos das corporações, mas também profissionais da classe média, cujas famílias tinham de sacrificar as economias de toda uma vida para pagar resgates.

Enquanto a pobreza e a decadência urbana aumentavam, a consequência mais visível da quebra - e que mudou o ambiente político do México - foi o colapso do sistema financeiro. O setor bancário do México tinha sido ineficiente tanto antes como durante a nacionalização. A privatização em 1991 e 1992 aumentou a quantidade de capital disponível para o setor privado, mas a persistência de altas barreiras à entrada permitiu que os bancos domésticos evitassem ajustar-se às pressões do mercado e enfraqueceu a competitividade. Com os três maiores bancos alocando dois terços de todo o crédito, o preço de tomar dinheiro emprestado era assustadoramente alto.

Os consumidores mexicanos e os proprietários de pequenos negócios já esta- 
vam pagando taxas de juros muito mais altas antes da quebra do que seus pares em outros países. Além disso, como os novos banqueiros não tinham experiência de análise de risco e estavam sob pressão para conseguir os maiores lucros possíveis sobre os empréstimos, eles emprestaram sem cuidados. Hipotecas e crédito ao consumidor eram setores extremamente lucrativos, mas também carregavam o maior risco de inadimplência. Mesmo antes da desvalorização, o nível de empréstimos sem retorno era perigosamente alto.

À medida que a crise financeira fumegante atingia a fervura completa após a desvalorização, os bancos contribuíam para sua própria ruína. Num ambiente de terríveis incertezas e inflação volátil, eles aumentaram as taxas de juros de cerca de $18 \%$, para até $120 \%$. Nesse processo, eles fizeram do reembolso de empréstimos um ato irracional para a maioria dos que os tomavam. Os bancos também exigiram o pagamento de muitos créditos comerciais que haviam rolado rotineiramente, empurrando comerciantes de pequeno e médio porte para o limite e desencadeando uma onda de falências. O setor de crédito ao consumidor desmoronou numa inadimplência maciça que paralisou o sistema financeiro. Segundo algumas estimativas, cerca de um terço de todos os empréstimos mexicanos eram considerados sem retorno no início de 1996. Ao mesmo tempo, leis de falência antiquadas e um sistema jurídico ineficiente tornaram virtualmente impossível cobrar as garantias de devedores inadimplentes.

Dada a magnitude da crise econômica, o povo mexicano começou a se organizar independentemente, expressar suas queixas e fazer exigências. Em 1995 um pequeno grupo de devedores rurais chamado El Barzón explodiu no cenário nacional, rapidamente evoluindo para um movimento urbano com 2 milhões de membros, composto de devedores da classe média e negociantes, que se recusavam a pagar as usurárias taxas dos bancos. A organização oferecia aconselhamento e recursos legais, o que permitiu a muitos devedores confrontar os bancos e negociar com eles.

Ameaçando uma moratória nacional sobre os pagamentos bancários que cobravam mais de $50 \%$ de juros reais, El Barzón forçou o governo a abordar o problema do alívio de dívida. Sob a divisa "debo no niego, pero pago lo justo" (devo, não nego, mas pago o que for justo), a militância, a organização e a bem executada campanha de publicidade do grupo deram a El Barzón legitimidade junto ao público e respeito como uma poderosa força política perante os assustados funcionários do Ministério da Fazenda. O colapso financeiro permitiu que um obscuro movimento social localizado no interior do país se tornasse uma ameaça genuína à estabilidade financeira da nação.

O governo respondeu com uma série de esquemas de alívio de dívida cujo objetivo era arrefecer o ímpeto populista por uma inadimplência em massa. A ideia básica era reestruturar a dívida comercial e do consumidor através de um ajuste automático pela inflação e da limitação da taxa de juros real. No entanto, em virtude de uma mal executada campanha de informação e de preocupações persistentes sobre o cálculo da taxa de inflação, o governo só conseguiu reestruturar parte dessa dívida.

Logo após a desvalorização, o sistema bancário estava perto do colapso. Num 
esforço para estabilizar a indústria bancária, o governo começou em 1995 a impor exigências de capitalização mais rígidas. Como poucos bancos conseguiam atender aos novos padrões, o próprio governo forneceu o capital necessário, tomando posse das ações do banco como garantia. Grande parte do sistema bancário foi virtualmente renacionalizada. Embora quase todos os bancos tenham recorrido ao governo em busca de assistência, doze deles faliram imediatamente. Os acionistas perderam investimentos de aproximadamente US\$ 1,5 bilhões.

Consequências muito mais graves do que o esquema de capitalização foram trazidas pela assimilação por parte do governo dos empréstimos sem retorno. Com um terço de todos os empréstimos em atraso, a maioria dos bancos estava em risco de insolvência, despertando a perspectiva de um pânico entre os depositantes e uma corrida a todos os bancos, saudáveis ou não. Como o governo não estava em posição de bancar o dinheiro, ele elaborou um mecanismo de assistência financeira de emergência aos bancos que não exigia gastos públicos imediatos. A instituição usada por ele para reduzir o nível de créditos de liquidação duvidosa dos bancos foi o Fundo Bancário de Proteção à Poupança (Fobaproa), uma pequena agência criada durante a administração Salinas e vagamente inspirada na U. S. Federal Deposit Insurance Corporation. Para que o Fobaproa pudesse retirar dos registros um empréstimo sem retorno, um banco tinha de concordar em anular $25 \%$ do valor do empréstimo. Em troca, ele recebia um título de cupom zero a $10 \%$ por $75 \%$ do valor do ativo. ${ }^{12}$ Não é surpresa que virtualmente todos os bancos tenham participado.

Amplamente ignorado pela imprensa e pela oposição, o Fobaproa assumiu bilhões de dólares de créditos de liquidação duvidosa num esforço desesperado para recapitalizar o sistema bancário. A agência, pequena e sub-aparelhada, não impôs limites legais à quantidade de depósitos que poderia garantir. Ela possuía experiência limitada na análise dos registros bancários e nenhuma experiência na liquidação de ativos bancários no mercado aberto. Em 1998, o Fobaproa havia acumulado cerca de US\$ 65 bilhões em passivos, mas especialistas estimaram que apenas um terço desse total poderia ser um dia recuperado. Os onze maiores bancos do México respondiam por cerca de metade dos passivos do Fobaproa. Como eles tinham de pagar um quarto de perdas, estavam expostos a uma perda de mais de US\$ 5 bilhões. Pior ainda, eles poderiam perder mais bilhões em empréstimos podres não cobertos pelo Fobaproa. Tais números rivalizavam com o total do ativo líquido dos bancos.

\section{EFEITOS POLÍTICOS COLATERAIS DO SALVAMENTO DOS BANCOS}

Em abril de 1998 o presidente Zedillo mandou ao Congresso um pacote de reformas bancárias para livrar o México de seu caos financeiro. Enquanto algumas

\footnotetext{
12 Embora semelhantes às notas do tesouro mexicanas, esses títulos não podem ser comprados ou vendidos em qualquer mercado e não podem ser usados como garantias em transações financeiras.
} 
questões regulatórias despertaram reclamações na oposição ${ }^{13}$, a determinação central - a incorporação dos passivos do Fobaproa pela dívida formal do setor público - incendiou o Congresso. O governo argumentou que a medida era necessária para reforçar o sistema bancário e proteger inocentes poupadores que mantinham seus depósitos em bancos com problemas. Conferir condição de dívida pública às obrigações do Fobaproa daria confiança ao depositante e permitiria ao governo reestruturar suas obrigações através de instrumentos de financiamento-padrão e distribuir o ônus fiscal com o tempo.

O volume do socorro aos bancos era assustador. A carteira de US\$ 65 bilhões do Fobaproa chegava a quase $15 \%$ do produto interno bruto (PIB) do México, uma quantia igual a quase um terço dos ativos totais do sistema bancário e muito mais do que o capital total dos bancos. A proposta representava o maior aumento na dívida interna da história do México, de cerca de $28 \%$ do PIB para $42 \%$.

Os dois principais partidos de oposição, o Partido da Revolução Democrática e o Partido da Ação Nacional (PAN), acusaram o PRI de subscrever as dívidas de seus ricos e corruptos aliados com o dinheiro do contribuinte. A repulsa geral provocada por mais uma crise econômica custou ao PRI seu controle de muitos anos sobre o Congresso -em julho de 1997 o PRD e o PAN juntos conseguiram a maioria na Câmara dos Deputados. O Executivo não mais gozaria da aprovação inconteste a suas iniciativas políticas. Depois dessas críticas eleições intermediárias, a aprovação do pacote de salvamento dos bancos criado por Zedillo tornou-se o centro da luta pelo poder político no México.

Funcionários do governo advertiram o Congresso para que não brincasse de política com o bem-estar econômico do país. O subsecretário de Finanças Martin Werner declarou que os legisladores podiam escolher entre "governar para o futuro ou acertar antigas desavenças". ${ }^{14} \mathrm{Em}$ abril de 1998, alegando que o colapso financeiro só poderia ser evitado através de imediata ação legislativa, o presidente Zedillo pediu ao Congresso que convocasse uma sessão especial em agosto para aprovar o pacote de socorro aos bancos. A Câmara não apenas recusou o pedido, mas redobrou seus esforços para desacreditar a proposta.

O esquema de salvamento dos bancos criado por Zedillo uniu por um tempo os partidos de oposição ideologicamente divididos, que usaram três argumentos para atacar o socorro aos bancos. Primeiro, tanto o PAN quanto o PRD sustenta-

\footnotetext{
13 Disposições menos divulgadas incluem o aumento da autonomia do Banco Central, assunto controvertido porque o presidente em exercício era o ex-ministro da Fazenda Guillermo Ortiz, amplamente acusado de ter sido o responsável pelo fiasco do Fobaproa. Outra disposição, destinada a atrair o capital externo para o deficiente sistema bancário do país, era remover as barreiras existentes à propriedade estrangeira, o que desencadeou algumas queixas populistas sobre a perda do patrimônio nacional. Disposições menos controvertidas incluíam o aumento da autonomia dos reguladores financeiros, revendo a garantia de depósito de $100 \%$, e estimulando o pagamento e a cobrança das dívidas.
}

14 Wall Street Journal, 3 de junho de 1998, p. A 11 
ram que a recapitalização dos bancos violava a Constituição. Na verdade, eles alegavam que o então ministro da Fazenda Guillermo Ortiz e o governador do Banco de México Miguel Mancera haviam agido ilegalmente ao salvar os bancos, porque os passivos do Fobaproa nunca foram autorizados pelo Congresso. ${ }^{15} \mathrm{Como}$ disse o representante do PAN Carlos Plascencia, "o Fobaproa não é uma questão de sim ou não; essa proposta só nos ofende porque se refere a um aspecto de legalidade, não de negociação ". ${ }^{16}$

Segundo, a oposição argumentou que o Fobaproa havia levado o país à falência por incompetência e má gestão. Como não conseguiu obter informações básicas sobre os empréstimos, como a história creditícia dos devedores, essa agência inexperiente considerou demasiado difícil liquidar ativos de risco mesmo que por uma fração de seu valor de face. Além disso, como ela rapidamente assumiu inúmeros empréstimos com um mínimo de análise, foi acusada de promover o risco moral no mundo dos negócios, que viu uma ótima oportunidade para descarregar suas dívidas sobre os contribuintes.

Finalmente, as acusações politicamente mais explosivas diziam respeito ao favoritismo. Embora tecnicamente o Fobaproa fosse um plano de proteção aos depósitos, seu efeito mais imediato foi o de beneficiar muitos dos empresários ricos e inescrupulosos do México. Políticos de oposição, confiando nos próprios dados financeiros dos bancos e no testemunho de conhecidos criminosos financeiros, expuseram o que pareciam ser negócios vantajosos oferecidos a alguns dos mais poderosos homens de negócios do país e contribuintes de longa data do PRI.

Pela primeira vez na história, o Congresso se tornou uma ferramenta de investigação, fornecendo evidências que indicavam que ricos e bem relacionados homens de negócio haviam utilizado o Fobaproa para se livrar de pesadas obrigações financeiras. Políticos da oposição declararam em julho de 1998 que haviam obtido documentos do Fobaproa que sugeriam que somente 604 empréstimos feitos a alguns dos mais poderosos empresários do México representavam quase a metade dos passivos totais da agência - quase com certeza um exagero, mas politicamente eficaz. Uma semana depois, a despeito dos protestos do governo sobre as leis de sigilo bancário, o PRD revelou uma lista de nomes das 310 maiores empresas e pessoas cujos empréstimos em atraso haviam sido assimilados pelo Fobaproa. Entre esses nomes estavam criminosos financeiros notórios e várias das maiores corporações mexicanas.

\footnotetext{
${ }^{15}$ A base para acusação foi o artigo 9 da Lei da Dívida Pública, que estabelece que o Congresso autorizará o volume de endividamento líquido externo e interno necessário ao financiamento do governo e de outras entidades públicas federais. No entanto, de acordo com o procurador-geral Ismael Gómez Gordillo, como os ativos do Fobaproa eram privados, o salvamento do banco não estava sujeito às mesmas regras que governavam a dívida pública. Ver Reforma, 2 de junho de 1998, p. 1; e El Universal, 7 de agosto de 1998, p. 6.
}

${ }^{16}$ El Financiero, 11 de junho de 1998. 


\section{O BAILOUT DEAL ${ }^{17}$ E O ADVENTO DA POLÍTICA DOS PARTIDOS MEXICANOS}

Durante a maior parte do século, o PRI fora a arena exclusiva de negociação entre os diversos interesses econômicos. A manutenção obstinada de um regime cambial cada vez mais inviável sob o presidente Salinas, embora influenciada pelo aparecimento de poderosos partidos de oposição, refletia a persistência da hegemonia do PRI na política governamental. Num esforço para reaver o apoio do eleitorado tradicional do PRI, a liderança do partido - e apenas ela - concebeu, implementou e manteve a crawling peg. Em contraste, a política e os resultados políticos do socorro aos bancos sob o presidente Zedillo foram comandados por partidos de oposição sólidos e viáveis.

A tendência em direção a uma competição multipartidária mais autêntica aumentou aos poucos após o colapso do peso, particularmente durante o debate sobre o Fobaproa. Sendo o partido dominante de mais ampla base social, o PRI afastou-se da ideologia e retratou-se como um partido pragmático desejoso de abordar a ameaça de colapso financeiro com propostas políticas substantivas. No entanto, sob o peso da culpa pela crise, ele adotou também uma postura flexível e conciliatória para minimizar danos políticos posteriores. Como a voz da sobriedade econômica, o partido de centro-direita PAN viu-se numa situação difícil. Por um lado, seu núcleo eleitoral formado por pequenos negociantes exigia pronta resolução da crise financeira; por outro lado, qualquer cooperação com o PRI poderia facilmente ser vista pela esquerda como uma traição, o que poderia minar a capacidade do PAN de ampliar sua atração junto aos setores populares.

Enquanto isso, o PRD alimentava sua própria imagem como o único protetor da justiça social mexicana. Sua liderança percebeu que a cooperação entre os dois outros partidos poderia acabar levando a um compromisso político em relação ao pacote financeiro, e assumiu a posição de expor qualquer acordo legislativo como uma traição à confiança da população. Como explicou o analista político Luis Rubio, o "PAN reconhece a necessidade de aprovar a lei do governo de aumento da dívida, mas não deseja pagar um alto preço político por isso. O PRD roubou a agenda legislativa dos outros partidos e está fazendo tudo o que pode para aumentar o custo político de todo o acordo". ${ }^{18}$ Caracterizando as conversações no Congresso como uma farsa, o PRD anunciou publicamente sua saída das negociações em curso no outono de 1998 e dedicou-se a atacar qualquer progresso em direção a uma resolução como sendo antidemocrático e inconstitucional.

Como esperado, após meses de animosidade politicamente motivada, o PAN começou a cooperar com o PRI na elaboração de uma proposta alternativa ao tão amaldiçoado pacote de reformas financeiras de Zedillo. A iniciativa incluiu várias disposições destinadas a dar cobertura política para membros do Congresso que

\footnotetext{
17 Acordo de Assistência Financeira de Emergência aos Bancos. (N. do T.)

${ }^{18}$ Los Angeles Times, 13 de julho de 1998, p. A11
} 
desejavam acabar com a tática de ameaça legislativa. Primeiramente, negou cobertura a empréstimos acima de 5 milhões de pesos e incluiu no Fobaproa pequenas obrigações em cartões de crédito e hipotecas. O compromisso ajudou a desviar as críticas da população ao tornar os bancos responsáveis pelas dívidas das maiores empresas, que tinham menores custos administrativos; isso permitiria que os bancos aumentassem ostensivamente as taxas de cobrança. Em seguida, o novo pacote propiciava ajuda a pequenos devedores que haviam continuado a saldar seus empréstimos durante toda a crise, visando especificamente negociantes, fazendeiros e proprietários de pequeno e médio porte. A importância política desse eleitorado - a classe média urbana e os proprietários rurais - facilitou o compromisso entre o PAN e o PRI.

Finalmente, a legislação incorporou o pedido do PAN para eliminar o Fobaproa e realocar sua carteira para uma nova agência, o Instituto de Proteção à Poupança Bancária (IPAB). Através de uma série de manobras legais, o IPAB não transferiria oficialmente suas obrigações para a dívida pública. No entanto, como os críticos imediatamente apontaram, como as obrigações do IPAB seriam financiadas por uma alocação especial do orçamento federal, a mudança não representaria mais do que uma ficção legal que mantinha o espírito, se não a letra, da proposta original de Zedillo. A disposição também proibia a todos os funcionários públicos que haviam participado do socorro aos bancos em 1995 atuarem no conselho diretivo do IPAB. Embora o PAN tivesse desistido de continuar a reivindicar a demissão do ex-ministro da Fazenda Guillermo Ortiz, ele podia ao menos alegar que tinha evitado que o impopular banqueiro interferisse ainda mais no salvamento dos bancos.

Em 2 de dezembro de 1998, o PAN e o PRI aprovaram por maioria absoluta o pacote de reformas. ${ }^{19}$ Embora as implicações orçamentárias a longo prazo do socorro aos bancos continuassem sendo perturbadoras, tanto o PAN como o PRI se felicitaram publicamente por se terem colocado acima da política e salvado a economia do país. Os membros do PRD ficaram enraivecidos, chamando o Congresso de "traidores da pátria" e caracterizando os legisladores da direita como "prostitutas PANistas". ${ }^{20}$ Grupos de protesto do El Barzón dirigiram-se aos empurrões para o plenário do legislativo e bombardearam os membros do PAN e do PRI com farinha e tomates. O PRD se tinha deleitado em seu papel de sabotador político, mas também deu aos dois outros partidos a oportunidade de isolá-lo do eleitorado moderado majoritário. Tanto o PRI quanto o PAN caracterizaram o PRD como uma força que, se conseguisse poder real, destruiria o sistema financeiro para obter vantagens políticas.

O acordo sobre o Fobaproa manteve os bancos no centro da cena política no México. Em julho de 1999 foi concluída uma auditoria externa do salvamen-

\footnotetext{
${ }^{19}$ A votação foi de 325 a 159 na Câmara dos Depurados, com 12 PANistas e sete PRIistas votando com a oposição, e de 93 a 10 no Senado, dominado pelo PRI.
}

${ }^{20}$ Boletín Mexicano de la Crisis, 19-25 de dezembro de 1998, p. 10. 
to bancário encomendada pelo Congresso e há muito tempo aguardada. A auditoria de US\$ 20 milhões, conduzida pelo canadense Michael Mackey, concluiu que a crise resultara de deficiências significativas no processo de reprivatização dos bancos, de falta de experiência dos novos proprietários e de regulamentação deficiente por parte das autoridades governamentais. Dado que esses problemas surgiram durante o mandato de Salinas, os achados satisfizeram à administração Zedillo. No entanto, o relatório da auditoria também concluiu que o bombeamento de dinheiro para bancos insolventes havia custado aos contribuintes mexicanos muito mais do que custaria deixar que os bancos simplesmente falissem. A oposição concentrou seu foco na descoberta de que US\$ 8 bilhões do total de empréstimos eram de legalidade questionável, US\$ 638 milhões eram claramente ilegais e US\$ 4,4 bilhões envolviam empréstimos a empresas diretamente afiliadas. No entanto, o relatório de Mackey não conseguiu descobrir evidências de que algum funcionário do governo houvesse infringido a lei. Críticos desapontados acusaram o governo de ter usado a lei do sigilo bancário para negar à equipe de auditoria acesso às informações necessárias para comprovar casos específicos de criminalidade. $^{21}$

\section{AVALIANDO A CRISE: A REFORMA FOI EFICAZ?}

O debate sobre o que a desvalorização mexicana e suas sequelas nos ensinaram sobre reforma de política econômica é altamente polarizado. O México era um mercado emergente genuinamente reformista, cujo colapso financeiro pegou de surpresa tanto os críticos quanto os partidários da liberalização. Enquanto os primeiros retrataram a crise como um resultado inevitável da falta de restrição aos mercados, os últimos argumentaram que o sólido fundamento das reformas no México salvou o país do que poderia ter sido uma longa depressão.

Para os críticos da liberalização econômica, a desvalorização mexicana e a recessão subsequente mostraram evidências de que os mercados livres levam os países em desenvolvimento à crise, não ao crescimento. Se algum dos tão decantados mercados emergentes tinha condições de ter sucesso seguindo o Consenso de Washington, esse país seria o México. O governo estava genuinamente comprometido com a reforma, e suas autoridades financeiras estavam entre as mais tecnicamente capazes do mundo, tendo obtido doutorados em departamentos econômicos de universidades de elite dos EUA. Mas mesmo com esses trunfos, que poucos outros países em desenvolvimento podiam igualar, o governo implementou políticas incongruentes e insustentáveis que destruíram os ganhos obtidos através da disciplina fiscal. Além disso, continua a crítica, a liberalização não conseguiu salvar 90 milhões de mexicanos de uma recessão devastadora - e da consequente decadência do tecido social- apesar dos benefícios extraordinários de uma integração muito

\footnotetext{
${ }^{21}$ Julia Preston, “Runaway Banks without Brakes”, New York Times, 22 de julho de 1999, p. 3.
} 
próxima com a maior economia do mundo. A administração Clinton orquestrou uma assistência financeira de emergência de US\$ 50 bilhões com o Fundo Monetário Internacional, que injetou liquidez na cambaleante economia. A economia em expansão dos EUA absorveu então aumentos maciços nas exportações mexicanas. Como esperado, o déficit mexicano com os Estados Unidos rapidamente se transformou num grande superávit (ver figura 3.2). Mas o mexicano médio recebeu poucos benefícios da melhoria do desempenho econômico. Mesmo com uma moeda desvalorizada que tornou os bens mexicanos extremamente competitivos, a economia não conseguiu gerar crescimento ou empregos suficientes para proteger milhões da pobreza cada vez mais profunda. Na metade dos anos 90, a renda real per capita ainda não tinha voltado aos níveis de 1981.

Figura 3.2: Déficit na conta corrente do México, 1988-1997

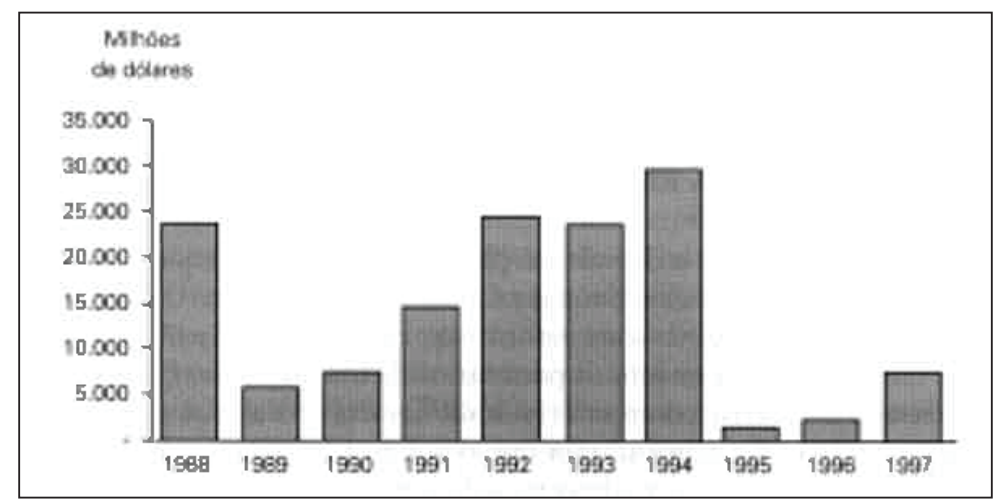

Fonte: Banco de México, Indicadores Econômicos

Finalmente, segundo sindicatos de trabalhadores, legislados protecionistas e especialistas dos Estados Unidos, a crise mexicana destruiu os empregos norte-americanos ao mesmo tempo que reduziu os padrões de vida dos mexicanos. Após a desvalorização, o peso enfraquecido tornou os bens mexicanos extremamente competitivos nos mercados dos EUA. O NAFTA, argumentou-se, havia sido um Cavalo de Tróia. O livre comércio trouxe uma nação em desenvolvimento aparentemente saudável e robusta diretamente para dentro do mercado norte-americano, com a promessa de que o crescimento continuado significaria uma expansão permanente do emprego no setor exportador, de altos salários. No entanto, em menos de um ano, a desvalorização do peso transformou consumidores norte-americanos na tábua de salvação da economia mexicana, que se agarrou à sobrevivência apenas através da exportação de grandes quantidades de bens para seu próspero vizinho do Norte.

A afirmação de que o México sofreu profundamente com o resultado da desvalorização é indiscutível. No entanto, o argumento de que a liberalização econômica do México causou a quebra do peso mistura erros específicos de política com a reforma econômica geral. O colapso financeiro não foi resultado da liberalização do comércio e do investimento ou da maior eficácia fiscal. Ao contrário, a abertura dos 
mercados de capital e do setor bancário, rápida e sem regulamentação, combinada com uma insustentável política cambial, foram os principais fatores por trás da crise.

Os defensores da liberalização sustentam - com consideráveis evidências - que a reforma estrutural e a abertura permitiram à economia mexicana recuperar-se de erros de atuação e de choques exógenos muito mais rapidamente do que com uma política voltada para dentro. Desde que a taxa de câmbio começou a flutuar, o crescimento voltado para o exterior provou ser bastante viável e dinâmico. Embora a recessão que se seguiu à desvalorização tenha sido com certeza a mais profunda do século, a disciplina fiscal e um clima de abertura nos negócios, que deu as boas-vindas ao investimento externo, ajudaram o México a transformar um declínio de 6,2 \% no PIB em 1995 num robusto crescimento durante os três anos seguintes (ver figura 3.3). Ao contrário, a desvalorização de 1982 havia mergulhado o México numa década de inflação e estagnação.

Figura 3.3: Crescimento do PIB Mexicano, 1994- 1998

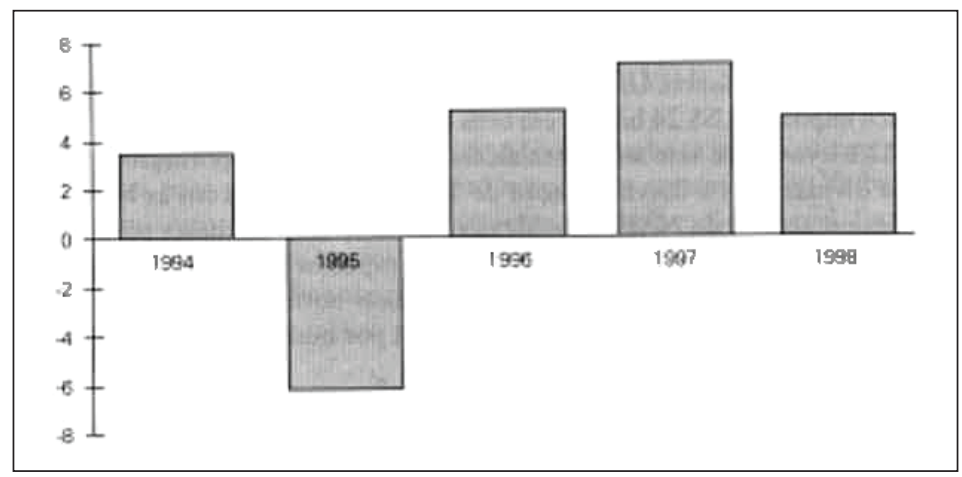

Fonte: Banco de México, Indicadores Econômicos

A principal razão para a recuperação, é claro, foi o aumento do comércio com os Estados Unidos. Mas tão importante quanto a expansão das exportações mexicanas foi sua composição. Como resultado da redução de barreiras ao investimento externo, o México não é mais apenas uma linha de montagem para insumos importados. Os mexicanos estão participando cada vez mais de atividades de produção e distribuição de alto valor agregado, como pesquisa e desenvolvimento, engenharia e marketing, tanto para os mercados domésticos com o para os externos. Empresas "maquiladoras" tradicionais ainda são uma presença importante nas atividades exportadoras, mas empregos muito mais profissionais e técnicos estão atualmente sendo gerados ao sul do Rio Grande. Além disso, a expansão industrial do México não está mais concentrada exclusivamente na região fronteiriça. ${ }^{22}$

\footnotetext{
22 Ver Geri Smith e Elizabeth Malkin, “Mexican Makeover”, Business Week, 21 de dezembro de 1998, pp. 50-2.
} 
Ainda mais impressionante é o México ter conseguido tais resultados apesar de severos choques exógenos. A queda nos preços internacionais do petróleo forçou o governo a cortar o orçamento por três vezes em 1998 e reduziu as receitas em divisas, enquanto o colapso financeiro do Leste da Ásia e da Rússia fez com que os investidores globais evitassem indiscriminadamente os mercados emergentes. A capacidade do México de continuar crescendo apesar da diminuição dos gastos públicos e das entradas de capital externo continua contrastando com as experiências de outros mercados emergentes que enfrentam restrições similares. Esse desempenho reflete a eficácia de reformas fundamentais no gerenciamento fiscal, no comércio e nos investimentos.

Quanto ao impacto regional, longe de prejudicar a economia dos EUA, a reforma no México ajudou a proteger seu vizinho de choques econômicos geralmente associados à desvalorização de um parceiro comercial importante. Evidências de qualquer retardo econômico foram escassas. Nos anos que se seguiram à crise, a expansão econômica nos Estados Unidos na verdade se acelerou. À medida que seu PIB galopava à frente de quase todos os países desenvolvidos, a inflação dos EUA continuava desprezível - em contraste com a do México (ver figura 3.4) -, o desemprego caía para o mais baixo nível em 30 anos, o mercado de ações disparava e o governo federal começava a acumular grandes superávits fiscais. E embora o México tenha realmente gerado um grande superávit comercial com os Estados Unidos, o nível real de exportações dos EUA para o México e os empregos associados a ele variaram pouco. Uma vez mais a comparação é esclarecedora. Enquanto o México importou US\$ 24 bilhões em bens em 1981, importou apenas US\$ 9 bilhões em 1983 e levou mais sete anos para alcançar os níveis de importação anteriores à crise da dívida; após a desvalorização de 1994, no entanto, com as baixas tarifas incluídas no acordo da NAFTA, o México levou apenas 18 meses para recuperar seus níveis de importação de antes da crise. Ao exportar mais bens para o mercado norte-americano, o México não roubou empregos norte-americanos, mas apenas tomou o lugar de bens previamente exportados por outros mercados emergentes.

Figura 3.4: Taxa de Inflação

Mexicana, $1994-1998$

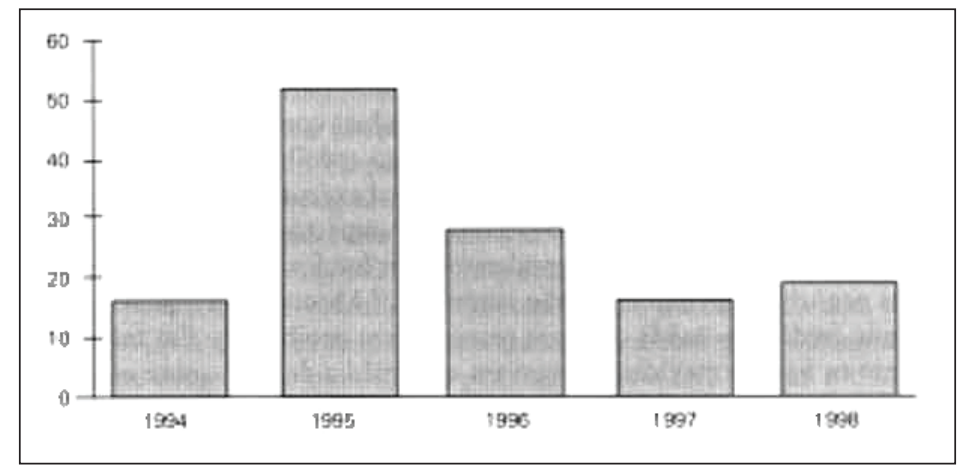

Fonte: Banco de México, Indicadores Econômicos 
A transformação econômica do México não eliminou a pobreza geral e a desigualdade social de longa data, e a "economia dual” é mais evidente do que nunca. Milhões de cidadãos não estão ainda sequer integrados à economia interna, e muito menos a mercados globais de exportação. Mas o argumento contra a liberalização se baseia na afirmação implausível de que o emprego e os salários estariam de alguma forma em melhor situação sem as reformas. Embora as exportações isoladamente não possam tirar da pobreza milhões de camponeses e subempregados, a integração do México nos mercados de bens tradicionais e sofisticados é essencial para gerar empregos de qualidade, o que por sua vez cria demanda tanto para a educação básica quanto superior. A abertura econômica não foi uma panaceia para o desenvolvimento mexicano, mas abreviou dramaticamente o que poderia ter sido outra década perdida de crise, e proporcionou a disciplina macroeconômica e as oportunidades comerciais das quais dependerá o futuro crescimento.

\section{ALÉM DA REFORMA: O DESAFIO DE DESENVOLVIMENTO DO MÉXICO}

As realizações do setor exportador do México, embora significativas, não serão suficientes para gerar um crescimento econômico sustentado ou de base ampla. Mais fundamentalmente, falta ao México um setor bancário viável. Enquanto quase todos os setores econômicos importantes se recuperaram desde a desvalorização de 1994, o sistema financeiro permaneceu imerso na crise e incapaz de fornecer crédito para o investimento produtivo. ${ }^{23} \mathrm{O}$ capital externo tornou possíveis investimentos consideráveis desde a quebra do peso, mas não será um substituto para o desenvolvimento doméstico.

Apenas as maiores corporações do México têm acesso regular ao capital bancário. ${ }^{24}$ Ainda sem capacitação na análise de risco e desesperados para evitar novos empréstimos ruins, os bancos evitam emprestar para pequenos negociantes ou para pessoas físicas. Mesmo as grandes companhias com capital suficiente para se expandir vão sendo enfraquecidas pelo contínuo encolhimento do crédito doméstico. De acordo com Ignacio Toussaint, principal executivo financeiro do segundo maior varejista do México, o Grupo Gigante, "O impacto é indireto através de nossos clientes e fornecedores. Se eles não puderem obter fundos para compras ou reinvestir em seus negócios, eles não crescerão conosco" ${ }^{25}$ Mesmo para aqueles que

\footnotetext{
${ }^{23}$ Ver Thomas W. Slover, “Tequila Sunrise: Has Mexico Emerged from the Darkness of Financial Crisis?”, in NAFTA: Law and Business Review of the Americas, vol. 5 (inverno de 1999), pp. 91-135.

${ }^{24}$ Uma das primeiras tarefas do IPAB foi criar novas regras que permitissem ·aos bancos manter títulos do governo não negociáveis para trocá-los por dívidas negociáveis. Embora essa medida aumente a liquidez do sistema bancário e coloque mais crédito à disposição do setor privado, ela não poderá melhorar a capacidade dos bancos quanto à análise de risco e não é provável que consiga reverter sua aversão a conceder empréstimos.

${ }^{25}$ Citado in Matthew Doman, “Crying Out for Corporate funding”. Euromoney (setembro de 1998), p.156.
} 
podem conseguir crédito, as taxas de juros permanecem proibitivas. Em maio de 1999, enquanto os bancos mexicanos pagavam uma média de 10\% sobre os depósitos a longo prazo, eles cobravam $37 \%$ sobre os empréstimos para compra de carros e $55 \%$ sobre os cartões de crédito, um dos mais altos spreads do mundo. ${ }^{26}$

Apesar das enormes obrigações assumidas pelo Fobaproa, os bancos mexicanos ainda são instituições frágeis. O chefe do IPAB Vicente Corta colheu elogios por ações duras, como assumir o controle e leiloar os bens da Banca Serfín, terceiro maior banco do México e financeiramente insolvente. Tendo em vista que o banco era controlado por Adrián Sada, um industrial poderoso e politicamente bem relacionado, a insistência do IPAB em que os proprietários perdessem 100\% de seus investimentos lhe conquistou o respeito até mesmo dos políticos da oposição. ${ }^{27}$ No entanto, a fraqueza do sistema bancário é geral. Em junho de 1999 a Moody ‘s Investors Service relatou que os bancos mexicanos ainda estavam US\$ 13 bilhões aquém da capitalização adequada. ${ }^{28}$ Dos 74 países cuja estabilidade do sistema bancário é avaliada pela Moody's, o México detinha o nono pior lugar, abaixo do Cazaquistão, da Romênia e da Tunísia. ${ }^{29}$

O setor privado do México reconheceu que o deficiente sistema bancário do país limita as oportunidades de crescimento. A perspectiva de um prolongado encolhimento do crédito despertou ideias que teriam sido impensáveis alguns anos atrás. No início de 1999 alguns dos empresários mais influentes do país propuseram a dolarização formal da economia - um plano já articulado pelos governos da Argentina e do Equador. ${ }^{30}$ Eugenio Clariond, presidente do Conselho Mexicano de Homens de Negócios (CMHN), um órgão de elite, pediu publicamente ao presidente Zedillo que endossasse um plano para permitir às firmas mexicanas realizar transações básicas em dólar. Ele prosseguiu explicando que os benefícios resultantes da inflação baixa, do crescimento e das baixas taxas de juros poderiam estabelecer os fundamentos de uma eventual união monetária com os parceiros do México na NAFTA. Zedillo rejeitou enfaticamente a ideia, sustentando que o instrumento mais efetivo para reduzir a volatilidade financeira era a flutuação da

\footnotetext{
${ }^{26}$ Mark Stevenson, “Mexico to Subsidize Banks”, Associated Press, 9 de junho de 1999.

${ }^{27}$ Henry Tricks, "Bank Seizure Is at Heart of a Tougher Mexican Strategy”. Financial Times, 23 de junho de 1999 , p.5.

28james Smith, “Banking System Remains Mexico's· Achilles Heel”. Los Angeles Times, 24 de junho de 1999, p.C1.

${ }^{29}$ Caroline Brothers, "Mexico's Serfin Cheaper to Save than Sink", Reuters Financial Report, 28 de junho de 1999.

${ }^{30}$ A proposta da Argentina de dolarização não foi levada muito a sério pela comunidade financeira internacional ou, o que é mais importante, pelos Estados Unidos, porque os laços de integração da Argentina com o bloco norte-americano são fracos. Embora uma área de moeda dolarizada para o México fosse com certeza mais plausível, dado o rápido crescimento dos laços econômicos entre os três países da NAFTA, a resposta da administração Zedillo sugere que ainda pode levar algum tempo para que a política interna do México se adapte a essa ideia. Ver J. P. Morgan, "Monetary Union in the Americas", Economic Research Note, 12 de fevereiro de 1999.
} 
taxa de câmbio. ${ }^{31}$ É improvável que as cautelosas autoridades financeiras governamentais aceitem o risco de dolarização num futuro próximo, mas o fato de que o CMHN, a Associação dos Banqueiros do México e a maior câmara industrial do país tenham levado a sério a sugestão indica que o setor privado do México está profundamente preocupado com o potencial de desenvolvimento atual do país.

A lógica por trás da dolarização é aprofundar a integração do México com a economia dos EUA, uma estratégia que deu bons resultados durante o último notável boom dos anos 90. Entretanto, a forte dependência do México com relação ao mercado dos EUA - destino de mais de $80 \%$ dos US\$ 115 bilhões de exportações do México cm 1998 - terá severas consequências se o seu parceiro do norte cair em recessão, e nisso reside o risco da dolarização para o México.

O governo mexicano está bastante consciente da necessidade de diversificar seus mercados exportadores. O déficit em conta corrente, virtualmente eliminado após a desvalorização, voltou pouco a pouco a mais de US\$ 7 bilhões em 1997 e tem continuado a crescer. Embora o México esteja vendendo mais do que nunca, seu persistente desequilíbrio comercial sugere uma dependência estrutural das importações que poderia mais uma vez colocar em risco a estabilidade macroeconômica. Em 1999, o México concluiu negociações sobre acordos de livre comércio com a União Europeia (que comprou apenas US\$ 4 bilhões de bens mexicanos em 1998) e Israel. Ambos passaram a vigir a partir de $1^{\circ}$ de julho de 2000. Além disso, em 2000 o México estabeleceu acordos comerciais com a Guatemala, Honduras e El Salvador como um bloco. Tais acordos criarão importantes oportunidades para os produtores mexicanos, mas seus efeitos ainda serão minúsculos comparados à NAFTA. De qualquer modo, o crescimento mexicano estará sempre ligado à saúde da economia dos EUA num futuro próximo.

\section{CONCLUSÃO: O LEGADO POLÍTICO DA CRISE}

À luz da reviravolta do México, é provável que uma consequência duradoura da atual crise seja a continuidade da política e o gradual aprofundamento da reforma estrutural. Ainda que os principais arquitetos da liberalização do México, Salinas, Serra e Ortiz, tenham sido considerados culpados pelo colapso, o projeto econômico original continua vivo. Nem mesmo os mais francos políticos do PRD reivindicam a volta à substituição de importações, ao protecionismo ou à propriedade estatal da produção.

Os principais debates sobre o papel adequado do governo referem-se à corrupção, à competência administrativa e regulatória e a questões básicas de proteção social e redistribuição. O populismo está longe de ter desaparecido da política mexicana, mas não reverterá as transformações fundamentais do comércio e dos

\footnotetext{
${ }^{31}$ Adolfo Garza, "Mexican Businessmen, President at Odds over Dollarization”, Associated Press, 13 de março de 1999.
} 
investimentos mexicanos. É provável que mesmo o processo de orçamento, sujeito a muito mais pressão política interna do que as políticas econômicas que afetam o capital externo ou o acesso aos mercados, permaneça disciplinado, independentemente de qual partido esteja no poder.

A oposição generalizada à volta do paternalismo do PRI - como evidenciado pela dramática vitória do candidato do PAN, Vincente Fox, na eleição presidencial de julho de 2000 - indica uma transformação ainda mais profunda do Estado mexicano. Na verdade, a consequência mais permanente da crise foi a abertura do próprio processo político. Embora a desvalorização do peso em 1994 não tenha sido a causa direta da liberalização política do México ou da vitória de Fox, ela permitiu aos partidos de oposição explorarem oportunidades de abertura política como nunca antes. Não apenas acelerou o processo de democratização, mas também forjou a natureza da competição política e o processo legislativo num país que, até onde se pode lembrar, foi sempre governado por um único partido.

Isso não era para acontecer. $\mathrm{O}$ projeto de reforma de Salinas que acelerou o processo começou com o presidente de la Madrid, e era baseado numa clara sequência estratégica. Como o Partido Comunista da China - e não como o da antiga União Soviética - o PRI reestruturou a economia antes de abrir o sistema político à competição real. Durante esse período crítico, o controle do partido sobre as principais organizações sociais permitiu-lhe minimizar a mobilização popular contra a reforma.

A história sugere que a estratégia do PRI era bem fundamentada. Quando Salinas ganhou as eleições de 1988, a notável força eleitoral da esquerda e a revolta popular contra as irregularidades na contagem dos votos alertaram o PRI para o fato de que ele não mais conseguiria manter o controle da presidência pela fraude. Seis anos depois, a recuperação da estabilidade econômica e a melhoria aparente nos padrões de vida - em ampla medida resultantes de uma política cambial insustentável - haviam convencido o eleitorado a ficar com o PRI. Ernesto Zedillo conquistou a presidência em 1994 numa eleição relativamente limpa.

O choque da quebra do peso coincidiu com o surgimento de partidos de oposição bem organizados e profissionais que deram aos votantes, pela prime ir a vez, alternativas políticas reais. A desvalorização foi o principal catalisador de um evento político chave que encerrou o mais duradouro Estado de partido único do mundo. A vitória do PANista Vincente Fox na eleição presidencial de julho de 2000 foi claramente o ponto mais baixo da história do PRI. Mas seria prematuro escrever o obituário do partido. O PRI ainda tem vantagens em termos de experiência e recursos, e é ainda o único partido com ampla presença organizacional em todo o México. Se o PRI conseguir reinventar-se e voltar ao poder, ele o fará numa democracia cuja chegada foi apressada pelos seus próprios erros de atuação politicamente motivados. 